\title{
Reduction of long-term effects of local heating of the testis by treatment of rats with a $\mathrm{GnRH}$ agonist and an anti-androgen
}

\author{
B. P. Setchell ${ }^{1 *}$, L. Plöen ${ }^{2}$ and E. M. Ritzen ${ }^{1}$ \\ ${ }^{1}$ Pediatric Endocrinology Unit, Karolinska Hospital Q 02:08, Stockholm, Sweden; and \\ ${ }^{2}$ Department of Anatomy and Histology, Faculty of Veterinary Medicine, Swedish University \\ of Agricultural Sciences, Uppsala, Sweden
}

Heating the testes of anaesthetized adult rats to $43^{\circ} \mathrm{C}$ for $30 \mathrm{~min}$ in a waterbath was followed by a large decrease in testis and epididymis mass and number of spermatozoa 35 days later. These parameters had recovered to some extent, but not completely, by days 70 and 97 after heating, but had decreased again in rats examined on day 182. There were no consistent effects of heating on androgen status, as determined by the concentrations of testosterone in blood and testis fluids, or by seminal vesicle mass, and interstitial fluid volume was increased in the heated testes. Treatment of rats with an implant of a GnRH agonist and daily injections of an anti-androgen for 14 days (sufficient in itself to cause large temporary decreases in tissue mass,

\section{Introduction}

The damaging effects of whole body or local heating on the testes of mammals are well known and, although recovery begins about 40 days after a single exposure, even 60 or more days later, there is still a significant reduction in testis mass (for review, see Setchell, 1998). Repeated applications of heat to the testes of rats causes a reduction in testis mass that lasts many months (Bowler, 1972).

The effects of the drugs cyclophosphamide or procarbazine on spermatogenesis can be reduced by pretreatment of the rats with an antagonist or an agonist of $\mathrm{GnRH}$ combined with the anti-androgen flutamide (Kangasniemi et al., 1995a,b; Meistrich et al., 1995). Similarly, the effects of irradiation on spermatogenesis can be minimized by pretreatment of the rats with $\mathrm{GnRH}$ analogues, either agonists or antagonists (Shetty et al., 2000; Shuttleworth et al., 2000), and treatment with a GnRH agonist is effective even when given after the radiation (Meistrich and Kangasniemi, 1997). In rats with suppressed spermatogenesis resulting from administration of 2,5-hexanedione, treatment with a $\mathrm{GnRH}$ agonist results in reversal of the testicular atrophy and normalized stem cell factor expression (Blanchard et al., 1998).

In the present study the response of the testis to local

*Present address: Department of Anatomical Sciences, University of Adelaide, Adelaide 5005, Australia

Email: brian.setchell@adelaide.edu.au number of spermatozoa and androgen status) did not reduce the initial decrease in testis mass or number of spermatozoa seen after heating, but reduced the later decreases in mass and number of spermatozoa significantly. These findings indicate that, as well as causing damage to spermatocytes and spermatids, as previously reported, heating also reduces the ability of spermatogonia to repopulate the seminiferous tubules at longer intervals after heating. Furthermore, it appears that this effect on the spermatogonia can be reduced by treating the animals with a GnRH agonist and anti-androgen, a treatment similar to that shown by other authors to improve recovery of the testis from irradiation or drug treatment.

heating in rats treated with a GnRH agonist and an antiandrogen was examined, and the time of observation was extended to investigate whether the testis would eventually make a full recovery.

\section{Materials and Methods}

\section{Animals}

A total of 80 adult Sprague-Dawley strain rats (B and $\mathrm{K}$ Universal, Sollentuna) aged about 50 days and weighing about $280 \mathrm{~g}$ at the start of the experiment were used. The rats were anaesthetized with pentobarbitone sodium (Apoteket, Stockholm, $50 \mathrm{mg} \mathrm{kg}^{-1}$ i.p.) and the scrotum and hind legs of 48 of them were immersed for $30 \mathrm{~min}$ in a waterbath held at $43^{\circ} \mathrm{C}$. Immediately after the heating, half the heated animals and half the controls were given an implant of a GnRH agonist Zoladex (3.6 mg, Zeneca Pharmaceuticals, Macclesfield), and the first of 14 daily s.c. injections of an anti-androgen, flutamide $\left(20 \mathrm{mg} \mathrm{ml}^{-1}\right.$ in sesame oil:ethanol 50:50, $1 \mathrm{ml} \mathrm{kg}^{-1}$, Schering-Plough, Stockholm). The animals were weighed and checked at frequent intervals until sampling.

\section{Sampling}

At various times afterwards (Table 1), groups of rats from the four treatment groups were anaesthetized again and a blood sample was removed from the surface veins of one testis, which was then removed, weighed and decapsulated. 
Table 1. Mass of one testis and one epididymis of rats after heating of the scrotal region $(\mathrm{H})$ or treatment with GnRH agonist and antiandrogen $(\mathrm{Z})$, or both treatments $(\mathrm{HZ})$

\begin{tabular}{|c|c|c|c|c|c|c|}
\hline & \multirow[b]{2}{*}{ Days after heating } & \multirow[b]{2}{*}{ Number of rats } & \multicolumn{4}{|c|}{ Treatment (number of rats) } \\
\hline & & & $\mathrm{C}(4$ or 2$)$ & $\mathrm{H}(6$ or 3$)$ & $\mathrm{HZ}(6$ or 3$)$ & $\mathrm{Z}(4$ or 2$)$ \\
\hline \multirow[t]{5}{*}{ Mass of testis (g) } & 35 & 4 or 6 & $1.62 \pm 0.06$ & $0.70 \pm 0.03 *$ & $0.30 \pm 0.02^{+}$ & $0.38 \pm 0.01^{\neq \neq \neq}$ \\
\hline & 70 & 2 or 3 & $1.83 \pm 0.09$ & $1.03 \pm 0.06^{\mathrm{aa}}$ & $1.01 \pm 0.07$ aа & $0.87 \pm 0.08^{\neq \neq}$ \\
\hline & 97 & 2 or 3 & $1.69 \pm 0.01$ & $1.18 \pm 0.11^{\text {aaa }}$ & $0.95 \pm 0.09^{++, \text {aа }}$ & $1.40 \pm 0.03$ \\
\hline & 140 & 4 or 6 & $1.73 \pm 0.09$ & $1.11 \pm 0.10^{\text {aаa }}$ & $1.21 \pm 0.10^{++, \text {aаa }}$ & $1.63 \pm 0.02$ \\
\hline & 182 & 4 or 6 & $1.84 \pm 0.02$ & $0.88 \pm 0.05^{* * *, b b}$ & $1.38 \pm 0.09^{\text {t,aаa }}$ & $1.66 \pm 0.08$ \\
\hline \multirow[t]{5}{*}{ Mass of epididymis (mg) } & 35 & 4 or 6 & $440 \pm 28$ & $150 \pm 39$ & $160 \pm 38$ & $100 \pm 23^{\neq \neq \neq}$ \\
\hline & 70 & 2 or 3 & $510 \pm 20$ & $310 \pm 37^{a}$ & $170 \pm 3$ & $170 \pm 15^{\neq \neq}$ \\
\hline & 97 & 2 or 3 & $560 \pm 0$ & $420 \pm 64^{\text {aaa }}$ & $200 \pm 18^{+}$ & $380 \pm 20^{\ddagger}$ \\
\hline & 140 & 4 or 6 & $660 \pm 18$ & $360 \pm 43^{*}$,aа & $480 \pm 41$ & $540 \pm 22$ \\
\hline & 182 & 4 or 6 & $620 \pm 6$ & $310 \pm 18^{\text {aa }}$ & $440 \pm 68$ & $550 \pm 38$ \\
\hline
\end{tabular}

Values are means \pm SEM

All values for heat-treated testis or epididymis $(\mathrm{H})$ are significantly less than controls $(\mathrm{C})$.

Significantly different from day 35 : a $P<0.05$; aa $P<0.01$; aaa $P<0.001$.

Significantly different from day 97 or 140 : bb $P<0.01$.

Significantly different from HZ: $* P<0.05 ; * * * P<0.001$.

HZ significantly different from $\mathrm{Z}:{ }^{+} P<0.05 ;{ }^{++} P<0.01$.

Significantly different from $C$ : ${ }^{\ddagger} P<0.05 ;{ }^{\ddagger \ddagger} P<0.01 ;{ }^{\ddagger \neq \ddagger} P<0.001$.

The interstitial fluid was removed by irrigation with $4 \mathrm{ml}$ isotonic mannitol; the parenchyma was then forced through a 21 gauge needle with a $5 \mathrm{ml}$ syringe, and a cell and fluid fraction was separated by centrifugation at $10000 \mathrm{~g}$ for 15 min (Setchell et al., 1976; Turner et al., 1984). The other testis was also removed, weighed and fixed by pumping $0.9 \%(\mathrm{w} / \mathrm{v})$ sodium chloride followed by $4 \%(\mathrm{v} / \mathrm{v})$ glutaraldehyde in cacodylate buffer for about $5 \mathrm{~min}$ at a rate of $700 \mu \mathrm{l} \mathrm{min}{ }^{-1}$ with a peristaltic pump through a 25 gauge needle inserted into the testicular artery on the surface of the testis. In some of the smaller testes, the perfusion was not successful, and these testes were then fixed by immersion in the same fixative. All testes were stored in the same fixative until processing for histology. The seminal vesicles and epididymides were then removed and weighed, and the epididymides were frozen for determination of number of spermatozoa. Finally, a blood sample was removed by syringe and needle from the posterior vena cava, and the animal was killed with an overdose of anaesthetic.

Cubes of parenchyma (about $1 \mathrm{~mm}^{3}$ ) were cut from near the centre of each fixed testis, post-fixed in osmium tetroxide, dehydrated and embedded in Agar 100 resin. Semithin (about $1 \mu \mathrm{m}$ ) sections were cut on glass knives and stained with buffered toluidine blue. For preliminary examination, the slides were numbered so that the treatment was not apparent to the observer. At least six, and usually ten or more suitably orientated tubular crosssections from each animal were used for measurement of tubular diameter, which was done using a microscope fitted with a digital video camera and an image-analysis system. The number of suitable transverse tubular cross-sections depended on the actual size of the piece of tissue taken and the orientation of the tubules within the section. At the same time, each tubular cross-section was classified as normal if all generations of germ cells were present and there were no degenerating cells, or abnormal, if some cell types were missing or degenerating cells were present. The sections were then examined at higher magnification to determine the most advanced stage of spermatogenesis in the abnormal tubular cross-sections.

Blood samples were centrifuged at $3000 \mathrm{~g}$ for $15 \mathrm{~min}$ to separate plasma, which was stored frozen. The degree of dilution of the interstitial fluid in the isotonic mannitol was estimated by analysing it for sodium concentration by flame photometry, assuming that the concentration in the interstitial fluid was the same as in serum, as has been shown in other animals (Maddocks and Setchell, 1988; Zupp et al., 1988). Some of these diluted interstitial fluids, the tubular fluid fraction from the dispersed tubular cells and the plasma samples were analysed for testosterone by a fluorometric immunoassay (Delfia, Pharmacia, Stockholm, kindly performed by Karolinska Hospital Klinisk Kemi Department).

Spermatozoa were counted with a haemocytometer after maceration with an Ultraturrax of the epididymides and the cellular fractions of the testicular parenchyma in $0.9 \%$ sodium chloride containing $0.05 \%(\mathrm{v} / \mathrm{v})$ Triton X-100 (5 ml per tissue, followed by a further 1:10 dilution; Robb et al., 1978).

\section{Statistical analysis}

Data were analysed by analysis of variance, followed by least mean square test (Superanova; Abacus Concepts, 
Table 2. Mass of paired seminal vesicles with contents and initial body weight and daily body weight gain in control rats (C), and rats whose scrotal region had been heated $(\mathrm{H})$ or treated with $\mathrm{GnRH}$ agonist and anti-androgen $(\mathrm{Z})$, or both treatments $(\mathrm{HZ})$

\begin{tabular}{|c|c|c|c|c|c|}
\hline & \multirow[b]{2}{*}{ Days after heating } & \multicolumn{4}{|c|}{ Treatment } \\
\hline & & $\mathrm{C}$ & $\mathrm{H}$ & $\mathrm{HZ}$ & Z \\
\hline \multirow[t]{5}{*}{ Seminal vesicles (g) } & 35 & $1.66 \pm 0.20$ & $1.39 \pm 0.08^{* * *}$ & $0.07 \pm 0.005$ & 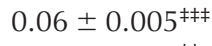 \\
\hline & 70 & $1.37 \pm 0.04$ & $1.60 \pm 0.03^{* * *}$ & $0.83 \pm 0.040$ & $0.67 \pm 0.020^{\ddagger \neq}$ \\
\hline & 97 & $1.63 \pm 0.07$ & $1.74 \pm 0.09 * *$ & $1.20 \pm 0.12$ & $1.49 \pm 0.05$ \\
\hline & 140 & $2.26 \pm 0.18^{a}$ & $1.92 \pm 0.09^{\dagger}$ & $1.56 \pm 0.08^{\dagger}$ & $1.87 \pm 0.10^{\neq \neq}$ \\
\hline & 182 & $2.01 \pm 0.14^{\mathrm{a}}$ & $1.96 \pm 0.09$ & $1.87 \pm 0.08$ & $1.75 \pm 0.13$ \\
\hline Initial body weight (g) & 0 & $284 \pm 4$ & $275 \pm 2$ & $279 \pm 3$ & $276 \pm 3$ \\
\hline \multirow[t]{7}{*}{ Weight gain $\left(\right.$ g day $^{-1}$ ) } & $0-7$ & $6.1 \pm 0.4$ & $5.6 \pm 0.1$ & $4.7 \pm 0.2$ & $4.8 \pm 0.2^{\ddagger \neq}$ \\
\hline & $7-17$ & $6.1 \pm 0.2$ & $6.1 \pm 0.2^{* * *}$ & $4.5 \pm 0.3$ & $3.4 \pm 0.3^{\ddagger \neq}$ \\
\hline & $17-36$ & $3.4 \pm 0.2$ & $3.2 \pm 0.2$ & $3.0 \pm 0.1$ & 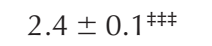 \\
\hline & $36-70$ & $3.2 \pm 0.1$ & $3.1 \pm 0.1$ & $3.5 \pm 0.1$ & $3.3 \pm 0.1$ \\
\hline & $70-97$ & $1.6 \pm 0.2$ & $1.7 \pm 0.2$ & $2.2 \pm 0.2$ & $2.3 \pm 0.1^{\neq \neq}$ \\
\hline & $97-140$ & $1.4 \pm 0.1$ & $1.5 \pm 0.2$ & $1.8 \pm 0.1$ & $1.7 \pm 0.1^{\ddagger}$ \\
\hline & $140-182$ & $0.9 \pm 0.1$ & $1.1 \pm 0.1$ & $1.2 \pm 0.2$ & $1.2 \pm 0.3$ \\
\hline
\end{tabular}

Values are means \pm SEM.

apooled data for days 140 and 180 after treatment are significantly different from pooled data for days 35, 70 and 97 .

Significantly different from $\mathrm{HZ}$ on same day after heating: $* * P<0.01 ; * * * P<0.001$.

Significantly different from $\mathrm{Z}$ on same day after heating: ${ }^{\dagger} P<0.05$

Significantly different from $C$ on same day after heating: ${ }^{\ddagger} P<0.05 ;{ }^{\ddagger \ddagger} P<0.01 ;{ }^{\ddagger \ddagger \ddagger} P<0.001$.

Berkeley, CA) for individual comparisons, by MannWhitney $U$ test when the data were not normally distributed or by chi-squared test.

\section{Results}

\section{Masses of testes, epididymides and seminal vesicles}

Thirty-five days after heating, the mass of the testes of rats heated but not treated with $\mathrm{GnRH}$ agonist and antiandrogen (H group) was less than half that of controls. There then followed a period of recovery up to day 97 after heating, when the mass of the testes had reached about $70 \%$ of that of controls. There was no change in the mass of the testes between day 97 and day 140 after heating. Thereafter, testis mass decreased again, so that by day 182 after heating, the mass of testes was again only half that of controls. At days 140 and 182 after heating, there was considerable variation between the masses of the two testes of individual rats and among rats within the group. The testes of the rats treated with $\mathrm{GnRH}$ agonist and antiandrogen ( $Z$ group) were reduced markedly in size at day 35 from the beginning of treatment, but recovered thereafter so that, by day 140 , they were not significantly different from controls. The heated testes of the rats that were treated with $\mathrm{GnRH}$ agonist and anti-androgen ( $\mathrm{HZ}$ group) were even smaller than those of the rats in group $Z$ at day 35 and remained so at days 97 and 140 . At days 70 and 182 after heating, the difference in size between $\mathrm{HZ}$ and $\mathrm{Z}$ rats was not significant, largely because of considerable variability in the $\mathrm{HZ}$ group. The testes of the $\mathrm{H}$ group were significantly smaller than those of the HZ group at day 182 after heating (Table 1).
In general, the masses of the epididymides showed a similar pattern, with those of the $\mathrm{H}$ group decreased at day 35 , recovering somewhat up to day 97 , after which time there were no further changes and epididymal mass remained less than that of controls for the rest of the experiment. In the $\mathrm{HZ}$ and $\mathrm{Z}$ groups, after the initial decrease, there was a steady recovery for the rest of the experimental period (Table 1 ).

The masses of the seminal vesicles were not different between the control and $\mathrm{H}$ groups, except for a small but significant reduction in the $\mathrm{H}$ group at day 140 after heating. In the $\mathrm{HZ}$ and $\mathrm{Z}$ groups, there was an initial decrease in seminal vesicle mass, indicating suppression of androgenic activity of the testis, and then recovery. After day 140 , seminal vesicle masses were not different from those of uninjected rats. In control rats, there was a small increase in seminal vesicle mass with age (Table 2).

Body weight gain up to day 35 after treatment was significantly lower in rats treated with $\mathrm{GnRH}$ agonist and anti-androgen, but thereafter, there was a faster weight gain (Table 2) so that at the end of the experiment, there were no significant differences in body weight among the groups (data not shown).

\section{Number of spermatozoa in testes and epididymides}

Numbers of spermatozoa in the testes and epididymides were reduced markedly after heating, showed a partial recovery up to day 97 and then decreased again. Numbers of spermatozoa were also reduced initially in both the $\mathrm{HZ}$ and $Z$ groups, and although the numbers of spermatozoa in the $\mathrm{HZ}$ group were often less than those in controls, they 
Table 3. Numbers of spermatozoa $\left(\times 10^{6}\right)$ in one testis and one epididymis of control rats $(\mathrm{C})$ and rats heated $(\mathrm{H})$ or treated with $\mathrm{GnRH}$ agonist and anti-androgen $(\mathrm{Z})$, or both treatments $(\mathrm{HZ})$

\begin{tabular}{|c|c|c|c|c|c|}
\hline & \multirow[b]{2}{*}{ Days after heating } & \multicolumn{4}{|c|}{ Treatment } \\
\hline & & $\mathrm{C}$ & $\mathrm{H}$ & $\mathrm{HZ}$ & Z \\
\hline \multirow[t]{5}{*}{ Testis } & 35 & $140 \pm 7$ & $3 \pm 1$ & $2 \pm 1$ & $1 \pm 0.2^{\ddagger \neq \neq}$ \\
\hline & 70 & $161 \pm 5$ & $43 \pm 30^{\text {aаa }}$ & $28 \pm 12$ & $39 \pm 32$ \\
\hline & 97 & $141 \pm 2$ & $73 \pm 40$ & $13 \pm 4^{t+t}$ & $122 \pm 4$ \\
\hline & 140 & $165 \pm 1$ & $38 \pm 22$ & $63 \pm 25^{+t}$ & $127 \pm 11$ \\
\hline & 182 & $209 \pm 4$ & $11 \pm 4^{* *, b}$ & $112 \pm 32^{+\dagger}$ & $168 \pm 20$ \\
\hline \multirow[t]{5}{*}{ Epididymis } & 35 & $258 \pm 33$ & $3 \pm 1$ & $7 \pm 3$ & $1 \pm 0.3^{\neq \neq \neq}$ \\
\hline & 70 & $280 \pm 10$ & $52 \pm 45^{\text {aa }}$ & $4 \pm 2$ & $5 \pm 4^{\neq \neq}$ \\
\hline & 97 & $296 \pm 12$ & $129 \pm 64$ & $1 \pm 1^{t+}$ & $168 \pm 23$ \\
\hline & 140 & $358 \pm 22$ & $94 \pm 56$ & $212 \pm 44$ & $289 \pm 14$ \\
\hline & 182 & $359 \pm 20$ & $61 \pm 3^{b c}$ & $157 \pm 71$ & $281 \pm 30$ \\
\hline
\end{tabular}

Values are means \pm SEM.

All values for heat-treated testis or epididymis $(\mathrm{H})$ are significantly less than controls $(\mathrm{C})(P<0.001)$ except on day 97 .

Pooled values for days 70 and 97 are significantly different from values for day 35 : aa $P<0.01 ;$ aaa $P<0.001$.

Values for day 182 are different from pooled data for days 70 and $97:{ }^{b} P<0.05$.

Values for day 182 are different from pooled data for days 70, 97 and 140 : ${ }^{c} P<0.05$.

Significantly different from $\mathrm{HZ}$ on same day after heating: ${ }^{* *} P<0.01$.

Significantly different from Z on same day after heating: ${ }^{++} P<0.01 ;{ }^{+++} P<0.001$.

Significantly different from $C$ on same day after heating: ${ }^{\ddagger \ddagger} P<0.01 ;{ }^{\ddagger \ddagger \ddagger} P<0.001$.

Table 4. Testosterone concentrations $\left(\mathrm{nmol} \mathrm{I}^{-1}\right)$ in blood plasma from the posterior vena cava (PVC) and testicular veins (TV) and interstitial (IF) and tubular (STF) fluids from the testes of heated $(\mathrm{H})$ and control $(\mathrm{C})$ rats

\begin{tabular}{cccccc}
\hline Days after heating & Treatment & PVC & TV & IF & STF \\
\hline \multirow{2}{*}{35} & H & $7.69 \pm 1.79$ & $1830 \pm 380$ & $2270 \pm 460$ & $1060 \pm 176^{\ddagger \neq}$ \\
& C & $9.17 \pm 2.56$ & $1200 \pm 250$ & $2150 \pm 470$ & $540 \pm 97$ \\
97 & H & $4.65 \pm 1.12$ & $1010 \pm 260$ & $1500 \pm 227$ & $558 \pm 125$ \\
182 & C & $2.70 \pm 0.19$ & $785 \pm 72$ & $1260 \pm 152$ & $417 \pm 63$ \\
& H & $3.57 \pm 0.32$ & $1320 \pm 146^{\ddagger}$ & $1370 \pm 250$ & $772 \pm 39^{\ddagger}$ \\
& C & $4.83 \pm 1.22$ & $722 \pm 77$ & $844 \pm 116$ & $499 \pm 55$ \\
\hline
\end{tabular}

Values are means \pm SEM.

Values for heated rats are significantly greater than those for controls for pooled data for three time points for TV, IF or STF by ANOVA: $P<0.05$.

Pooled values for IF are significantly greater than pooled values for TV, which are significantly greater than pooled values for STF by ANOVA: $P<0.001$.

Significantly different from $C$ on same day after heating: ${ }^{\ddagger} P<0.05 ;{ }^{\ddagger \ddagger} P<0.01$.

were higher than in the $\mathrm{H}$ group at day 182 after treatment (Table 3).

\section{Testosterone concentrations}

The concentrations of testosterone in the blood plasma from the posterior venae cavae were not different between the $\mathrm{H}$ and control groups. The concentrations of testosterone in testicular venous blood plasma, testicular interstitial fluid and seminiferous tubular fluid were all higher than they were in the posterior vena cava plasma and, in general, the concentrations found in the heated rats were slightly higher than those found in controls, although the differences were significant only for tubular fluid at days 35 and 182 and testicular venous blood plasma at day 182 after heating. The concentrations of testosterone in the interstitial fluid were slightly but significantly higher than those in the testicular venous blood, and both were higher than they were in the tubular fluid (Table 4).

\section{Fluid volumes}

The volume of interstitial fluid in the testis was increased initially after heating, then decreased, and increased again at days 140 and 182. A similar pattern was seen in the $\mathrm{HZ}$ rats, but there were no significant differences in rats from the $\mathbf{Z}$ group compared with the control group (Table 5).

The volume of tubular fluid was about $250 \mu \mathrm{g} \mathrm{g}^{-1}$ testis and showed no consistent differences among groups or with time (data not shown).

\section{Histological observations.}

The diameters of the seminiferous tubules were reduced by heating and by hormone treatment, and the combined 
Table 5. Interstitial fluid volumes ( $\mu \mathrm{I} \mathrm{g}^{-1}$ testis) in testes of control $(\mathrm{C})$ rats and rats that had been heated $(\mathrm{H})$ or treated with $\mathrm{GnRH}$ agonist and anti-androgen $(\mathrm{Z})$, or both treatments $(\mathrm{HZ})$

\begin{tabular}{ccccc}
\hline Days after heating & $\mathrm{C}$ & $\mathrm{H}$ & $\mathrm{HZ}$ & $\mathrm{Z}$ \\
\hline 35 & $85 \pm 7$ & $215 \pm 41^{\ddagger \neq}$ & $153 \pm 9$ & $116 \pm 11$ \\
70 & $80 \pm 11$ & $140 \pm 12$ & $100 \pm 6$ & $103 \pm 3$ \\
97 & $93 \pm 5$ & $128 \pm 30$ & $145 \pm 12$ & $101 \pm 11$ \\
140 & $86 \pm 12$ & $215 \pm 52^{\ddagger}$ & $173 \pm 27$ & $113 \pm 10$ \\
182 & $100 \pm 12$ & $350 \pm 47^{\ddagger \neq \neq, \mathrm{a}}$ & $282 \pm 60^{\ddagger \neq, \mathrm{a}}$ & $194 \pm 64$ \\
\hline
\end{tabular}

Values are means \pm SEM.

Values are significantly greater than controls: ${ }^{\ddagger} P<0.05 ;{ }^{\ddagger \ddagger} P<0.01 ;{ }^{\ddagger \neq \ddagger} P<0.001$

a $V$ alue significantly greater than at days 35, 70, 97 or 140: $P<0.05$.

Pooled values for $\mathrm{H}$ and $\mathrm{HZ}$ on days 35, 140 or 182 are significantly greater than pooled values for $\mathrm{C}$ and $\mathrm{Z}$ by two-factor ANOVA: $P<0.05$.

Table 6. Tubular diameters $(\mu \mathrm{m})$ in sections of testes of control rats $(\mathrm{C})$ and those that had been heated $(\mathrm{H})$ or treated with $\mathrm{GnRH}$ agonist and anti-androgen $(\mathrm{Z})$, or both treatments $(\mathrm{HZ})$

\begin{tabular}{|c|c|c|c|c|}
\hline Days after heating & $\mathrm{C}$ & $\mathrm{H}$ & $\mathrm{HZ}$ & Z \\
\hline 35 & $303 \pm 6.3$ & $193 \pm 6.1^{* *, \neq \neq \neq}$ & $163 \pm 8.8$ & $187 \pm 3.3^{\ddagger \neq \neq}$ \\
\hline 70 & $335 \pm 15$ & $250 \pm 26^{a}$ & $240 \pm 6^{a}$ & $255 \pm 15^{\ddagger}$ \\
\hline 97 & $300 \pm 20$ & $243 \pm 28$ & $283 \pm 9$ & $290 \pm 0$ \\
\hline 140 & $300 \pm 10$ & $242 \pm 22^{\mathrm{a}}$ & $248 \pm 24$ & $307 \pm 3$ \\
\hline 182 & $308 \pm 6.3$ & $190 \pm 8.6^{\ddagger \neq \neq, b}$ & $213 \pm 18^{t+t, c}$ & $317 \pm 6.7$ \\
\hline
\end{tabular}

Values are means \pm SEM.

a Value significantly different from that for day 35: $P<0.05$.

bValue significantly different from that for days 70 and 140: $P<0.05$.

'Value significantly different from that for day $97: P<0.05$.

Significantly different from $\mathrm{HZ}$ on same day after heating: ${ }^{* *} P<0.01$.

$\mathrm{HZ}$ significantly different from Z on same day after heating: ${ }^{+t+} P<0.001$.

Significantly different from $C$ on same day after heating: ${ }^{\ddagger} P<0.05 ;{ }^{\ddagger \neq \ddagger} P<0.001$.

Table 7. Numbers of tubular cross-sections and percentages of normal tubules in testes of control rats $(C)$ and those that had been heated $(\mathrm{H})$ or treated with $\mathrm{GnRH}$ agonist and anti-androgen $(\mathrm{Z})$, or both treatments $(\mathrm{HZ})$

\begin{tabular}{|c|c|c|c|c|c|c|c|c|}
\hline \multirow[b]{2}{*}{$\begin{array}{l}\text { Days after } \\
\text { heating }\end{array}$} & \multicolumn{2}{|c|}{$\mathrm{C}$} & \multicolumn{2}{|c|}{$\mathrm{H}$} & \multicolumn{2}{|c|}{$\mathrm{HZ}$} & \multicolumn{2}{|c|}{ Z } \\
\hline & $\begin{array}{l}\text { Number of } \\
\text { tubules }\end{array}$ & $\begin{array}{l}\text { Percentage } \\
\text { normal }(\%)\end{array}$ & $\begin{array}{l}\text { Number of } \\
\text { tubules }\end{array}$ & $\begin{array}{l}\text { Percentage } \\
\text { normal }(\%)\end{array}$ & $\begin{array}{l}\text { Number of } \\
\text { tubules }\end{array}$ & $\begin{array}{l}\text { Percentage } \\
\text { normal }(\%)\end{array}$ & $\begin{array}{l}\text { Number of } \\
\text { tubules }\end{array}$ & $\begin{array}{l}\text { Percentage } \\
\text { normal (\%) }\end{array}$ \\
\hline 35 & $62(8-24)$ & 100 & $111(6-50)$ & 0 & $246(15-68)$ & 0 & $126(18-49)$ & 0 \\
\hline 70 & $12(6-6)$ & 100 & $45(8-25)$ & 36 & $31(10-11)$ & 58 & $28(14-14)$ & 61 \\
\hline 97 & $39(18-21)$ & 100 & $82(22-31)$ & 51 & 40 (9-18) & $57^{+++}$ & $46(19-27)$ & 100 \\
\hline 140 & $56(9-25)$ & $84^{a}$ & $110(10-42)$ & 42 & $143(10-43)$ & $44^{+++}$ & $64(10-26)$ & 100 \\
\hline 182 & $73(14-28)$ & 100 & $172(9-38)$ & $6^{* * *}$ & $110(20-30)$ & $30^{++t}$ & $42(12-18)$ & 100 \\
\hline
\end{tabular}

Ranges of the numbers of suitable tubules per rat are given in parentheses.

a Abnormal all from one rat.

All percentage normal values for heated testes $(\mathrm{H})$ were less than those for controls $(\mathrm{C})$.

***Value significantly lower than that for $\mathrm{HZ}$ by chi-squared test: $P<0.001$.

${ }^{++}$Value significantly lower than that for $Z$ by chi-squared test: $P<0.001$.

treatments had a greater effect than either alone. In the $\mathrm{H}$ and $\mathrm{HZ}$ groups, the diameters returned towards normal, but decreased again at day 182 after heating (Table 6).

There was considerable variability in the histological appearance of seminiferous tubules within the same testis and among rats in the same treatment group. Detailed cell counts have not yet been completed but preliminary observations indicate that, in some abnormal tubular crosssections, both meiotic and post-meiotic cells were absent, with only spermatogonia and Sertoli cells present. In other abnormal tubules, the most advanced spermatogenic cells were spermatocytes, in others, round spermatids, and in others, elongated spermatids up to stage 16 . The testes of the rats in group $\mathrm{H}$ showed disrupted spermatogenesis in all rats at day 35 after heating. Thereafter, there was recovery in some tubules in most animals, and a subsequent deterioration at days 140 and 182 after heating (Fig. 1), although in most rats, complete spermatogenesis could be observed in 

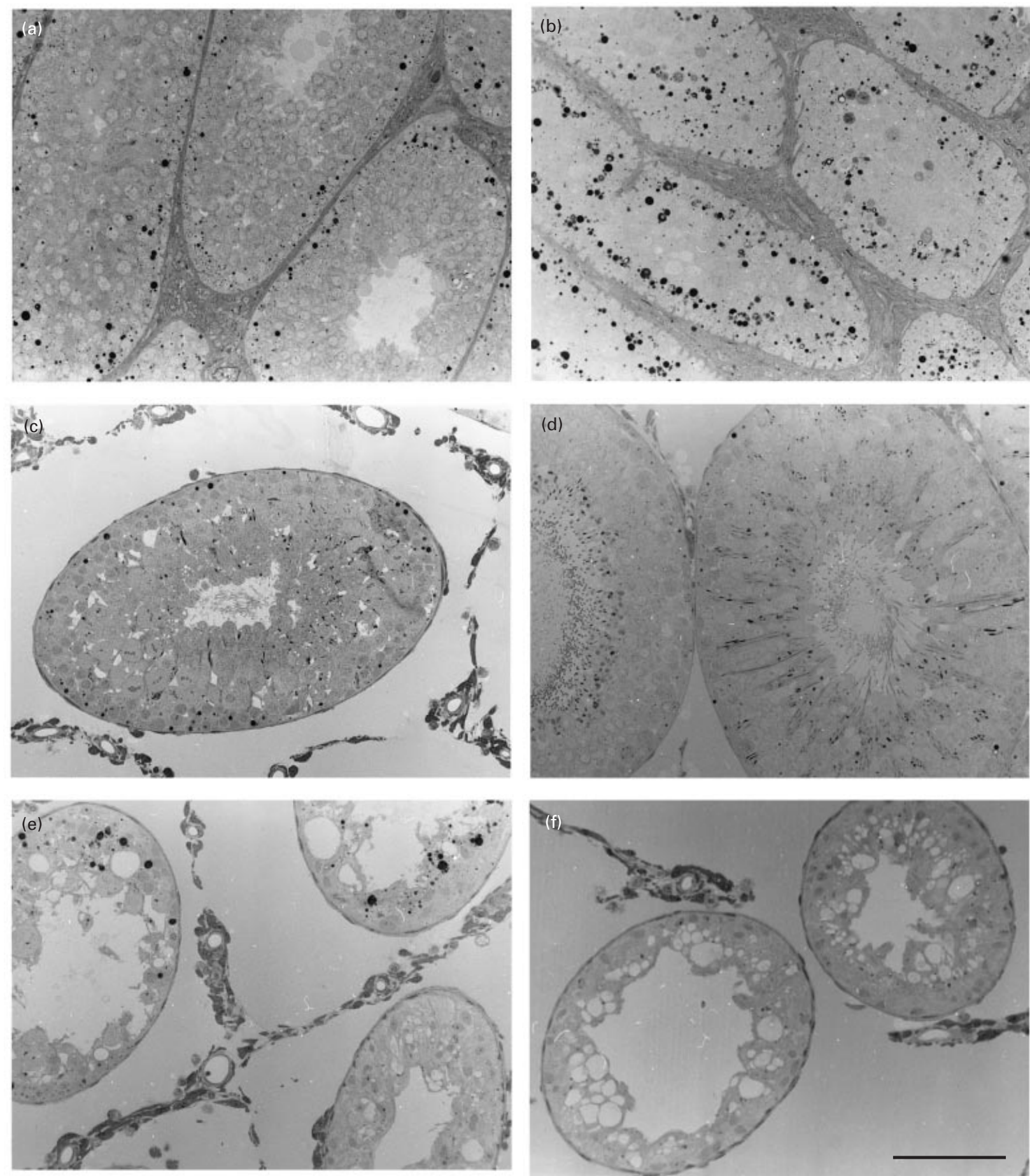

Fig. 1. Photomicrographs of sections of testes from rats treated 35 days earlier with GnRH agonist plus anti-androgen (group Z; a) and those that had also been heated at $43^{\circ} \mathrm{C}$ for $30 \mathrm{~min}$ (group $\mathrm{HZ}$ ) at day 35 (b) or day 182 after heating and treating $(\mathrm{d}, \mathrm{f})$, and from rats 182 days after heating that had not been treated with hormones (group H; c,e). Note that at day 35 after GnRH agonist and the start of anti-androgen treatment (a), spermatogenesis was disrupted, and the most developed cells were acrosome-phase spermatids. In hormone-treated rats heated 35 days earlier (b), few germ cells remained and there were numerous lipid droplets, with virtually no lumina. In rats examined at day 182 after heating, there was great variability in the appearance of the testis, both among animals and within one testis. One of the least and some of the most affected tubules in one heated rat in group $\mathrm{H}$ are shown (c,e) and a similar range of effects is shown in rats in group $\mathrm{HZ}(\mathrm{d}, \mathrm{f})$. However, in (d) there are some step 19 spermatids, whereas in (c), there are only a few elongated spermatids around step 13 or 14, and there were many more severely affected tubules in the rats in group $\mathrm{H}$. Scale bar represents $100 \mu \mathrm{m}$. 
some tubules. The percentage of tubular cross-sections showing a normal appearance increased to day 97 and then decreased again to a value $<10 \%$ at day 182 after heating, which was significantly lower than that in the $\mathrm{HZ}$ group at the same time. Spermatogenesis was also arrested at day 35 after heating in the $\mathrm{HZ}$ and $\mathrm{Z}$ groups, but all tubular crosssections were normal in the $Z$ groups by day 97 and thereafter. In the $\mathrm{HZ}$ group, there was a steady improvement in the percentage of normal tubules up to day 140 after heating, with a slight but significant deterioration thereafter. However, the percentage of normal tubules remained lower than it did in rats in the $Z$ group from day 97 after treatment onwards (Table 7).

\section{Discussion}

The most surprising finding in this study was the decrease in testis and epididymal masses and in the number of spermatozoa in the testis and epididymis in heated rats towards the end of the experiment, associated with a significant deterioration in the histology. This finding indicates that, as well as causing degeneration of spermatocytes and round spermatids, as has been reported by Chowdhury and Steinberger $(1964,1970)$ and Collins and Lacy (1969), a single short exposure of the testis to a moderate heat stress also inhibits spermatogonial recruitment and possibly the number of stem cells. Studies are currently being undertaken to test this contention by investigating the number of spermatogonia and other types of cell at various times after heating. An effect of heat on spermatogonia in mice had already been reported by Reid et al. (1981), who performed studies on the repopulation of seminiferous tubules after irradiation. Differentiation of spermatogonia has also been reported to be arrested in cryptorchid mice (de Rooij et al., 1999) and heating the testes of sheep caused a reduction in the production of $\mathrm{A}_{1}$ spermatogonia 20 days later, with no effect on the numbers of $\mathrm{A}_{0}$-spermatogonia (Hochereau-de Reviers et al., 1993). Miraglia and Hayashi (1993) reported a decrease in the percentage of tubules with spermatogonia from 100 to $89 \%$ at day 15 after heating the testes of rats to $43^{\circ} \mathrm{C}$ for $30 \mathrm{~min}$, as in the present study. This small but significant decrease was not as great as the decreases in the percentages of tubules with early or late spermatids (from 100 to 84 and $69 \%$, respectively). There was no decrease in the percentage of tubules with primary spermatocytes at that time.

The present results on the slow and incomplete recovery of testis mass after a single heat exposure are consistent with earlier studies. For example, Setchell et al. (1996), Setchell and Waites (1972), Galil and Setchell (1988), Main et al. (1978) and Bartlett and Sharpe (1987) found testis mass reduced to $68 \%, 70 \%, 47 \%, 57 \%$ and $44 \%$ at days 63,60 , 56, 50 and 42 after heating, respectively, which were the longest times examined in these studies. In most of these studies, testis mass reached a minimum of about $30-40 \%$ of controls between day 21 and day 28 after heating, although
Bartlett and Sharpe (1987) reported a decrease in testis mass up to day 42 after heating.

It is less surprising that inhibition of spermatogenesis immediately after heating by treatment of rats with a GnRH agonist and an anti-androgen did not reduce the decrease in testis mass and number of spermatozoa seen on day 35 after heating. The homogenization-resistant spermatid nuclei counted at this time would have been zygotene spermatocytes at the time of heating, assuming a spermatogenic cycle duration of 12.9 days (Russell et al., 1990) and there is no evidence to indicate that this treatment influences the degeneration of the spermatocytes.

The very low seminal vesicle masses, barely above those found in castrated animals, in the $\mathrm{Z}$ and $\mathrm{HZ}$ groups at day 35 after treatment confirm that treatment with $\mathrm{GnRH}$ agonist and anti-androgen reduced androgenic activity to negligible amounts. The sustained reduction in seminal vesicle mass in these animals indicates that there was a sustained suppression of androgen activity up to day 140 after the start of treatment, which was longer than expected. The decreased rate of gain of body weight during and immediately after the hormone treatment was also presumably a result of suppression of androgen concentrations in the circulation, but this effect persisted only until between day 70 and day 97 after treatment, indicating that body weight gain is less sensitive than the seminal vesicles to small reductions in androgenic activity. The higher concentrations of testosterone in the blood of the testis vein in heat-treated rats, despite the lack of any effect of heating on the concentration of testosterone in the peripheral blood, is also in accord with earlier studies (Galil and Setchell, 1988). Whether these higher concentrations of testosterone in the blood of the testis vein, mirrored in the concentrations in the interstitial and tubular fluids, are high enough to inhibit spermatogonial recruitment, as suggested by Meistrich et al. $(1996,2000)$ remains to be determined. The finding that the concentration of testosterone in testicular interstitial fluid was only slightly higher than that in testicular venous blood is in agreement with earlier studies in which interstitial fluid was collected with a push-pull catheter (Maddocks and Setchell, 1988, 1989a,b) and contrasts with the much higher values published for socalled interstitial fluid collected after death. The present values for seminiferous tubular fluid may be slight underestimates, because of a small dilution of this fluid with the mannitol solution used to remove the interstitial fluid, but this is not likely to be sufficient to explain the difference reported here between tubular fluid and interstitial fluid. A lower value for tubular fluid than interstitial fluid contrasts with the findings of Comhaire and Vermeulen (1976), who found similar concentrations in tubular and interstitial fluid collected by micropuncture. The present results also differ from those of Turner et al. (1984), who reported lower concentrations of testosterone in testicular venous blood plasma than in tubular fluid collected by micropuncture. The validity of the present technique for collecting interstitial fluid is supported by the estimates of volume 
collected, which are in good agreement with estimates of the volume of distribution for Cr-EDTA, a marker that is confined to the interstitial extracellular fluid and excluded from the tubular fluid (Setchell et al., 1996; Tao et al., 2000), and also for the volume of fluid that can be collected after death (Bartlett and Sharpe, 1987). Bartlett and Sharpe (1987) also reported an increase in the volume of interstitial fluid after heating of the testis, as observed in the present study. The reason for this increase, or its significance, has yet to be determined, but may simply be due to the reduced volume of the seminiferous tubules.

Administration of a potent and long-acting $\mathrm{GnRH}$ agonist effectively suppresses testosterone secretion by suppressing $\mathrm{LH}$ and $\mathrm{FSH}$ release for at least 28 days, by which time $92 \%$ of the depot preparation has been released (Furr and Hutchinson, 1992; Kangasniemi et al., 1995a). In the present study, the effect of any initial surge of testosterone was neutralized by the daily injection of a potent antiandrogen during the first 14 days of $\mathrm{GnRH}$ agonist treatment. In terms of the return to normal of testicular and seminal vesicle masses, and normalized testicular histology, the effects of the medication were undetectable by day 97 after treatment, and this finding is in agreement with the report that testis mass and the number of spermatozoa returned to normal by day 63 after the start of treatment (Kangasniemi et al., 1995b). Thus, the temporary suppression of the action of testosterone appears partially to protect spermatogenesis from the long-term damage caused by the heating. Whether this protection is due to reduced testosterone or gonadotrophins, or both, cannot be determined from the present results. It is possible that during the period of cell degeneration after heating, and the production of potentially toxic cytokines, stimulation of spermatogenesis by $\mathrm{FSH}$ and testosterone actually increases the damage.

The present results add to the previous observations of a protective effect of $\mathrm{GnRH}$ plus anti-androgen treatment on acute damage to spermatogenesis. Taken together, these studies give a background for prospective clinical trials, aiming at the protection of spermatogenesis during or after cancer treatment.

The authors are grateful to Zeneca Pharmaceuticals, Macclesfield, Cheshire for supplying the Zoladex implants and to Schering Plough $A B$, Stockholm for supplying the flutamide, to $\mathrm{Dr}$ Lars Olof Hansson for the testosterone assays and to the Nobel Foundation for financial support.

\section{References}

Bartlett JMS and Sharpe RM (1987) Effect of local heating of the rat testis on the levels in interstitial fluid of a putative paracrine regulator of the Leydig cells and its relationship to changes in Sertoli cell secretory function Journal of Reproduction and Fertility 80 279-287

Blanchard KT, Lee J and Boekelheide K (1998) Leuprolide, a gonadotropinreleasing hormone agonist, reestablishes spermatogenesis after 2,5hexandedione-induced irreversible testicular injury in the rat, resulting in normalized stem cell factor expression Endocrinology 139 236-244

Bowler K (1972) The effect of repeated applications of heat on spermatogenesis in the rat: a histological study Journal of Reproduction and Fertility 28 325-333

Chowdhury AK and Steinberger $\mathbf{E}$ (1964) A quantitative study of the effect of heat on the germinal epithelium of the rat testis American Journal of Anatomy 115 509-524

Chowdhury AK and Steinberger E (1970) Early changes in the germinal epithelium of rat testes following exposure to heat Journal of Reproduction and Fertility 22 205-212

Collins PM and Lacy D (1969) Studies on the structure and function of the mammalian testes II. Cytological and histochemical observations on the testis of the rat after a single exposure to heat applied for different lengths of time Proceedings of the Royal Society of London B 172 17-38

Comhaire FH and Vermeulen A (1976) Testosterone concentrations in the fluids of seminiferous tubules, the interstitium and the rete testis of the rat Journal of Endocrinology 70 229-235

De Rooij DG, Okabe M and Nishimune Y (1999) Arrest of spermatogonial differentiation in $j s d / j s d, \mathrm{Sl} 17 \mathrm{H} / \mathrm{Sl} 17 \mathrm{H}$, and cryptorchid mice Biology of Reproduction 61 842-847

Furr BJA and Hutchinson FG (1992) A biodegradable delivery system for peptides: preclinical experience with the gonadotrophin-releasing hormone agonist Zoladex Journal of Controlled Release 21 117-127

Galil KAA and Setchell BP (1988) Effects of local heating of the testis on testicular blood flow and testosterone secretion in the rat International Journal of Andrology 11 73-85

Hochereau-de Reviers MT, Locatelli A, Perreau C, Pisselet C and Setchell BP (1993) Effects of a single brief period of moderate heating of the testes on seminiferous tubules in hypophysectomized rams treated with pituitary extract Journal of Reproduction and Fertility 97 381-387

Kangasniemi M, Wilson G, Parchuri N, Huhtaniemi I and Meistrich ML (1995a) Rapid protection of rat spermatogenic stem cells against procarbazine by treatment with a gonadotropin-releasing hormone antagonist (Nal-Glu) and an antiandrogen (Flutamide) Endocrinology $1362881-2888$

Kangasniemi M, Wilson G, Huhtaniemi I and Meistrich ML (1995b) Protection against procarbazine-induced testicular damage by $\mathrm{GnRH}$ agonist and antiandrogen treatment in the rat Endocrinology $\mathbf{1 3 6}$ $3677-3680$

Maddocks S and Setchell BP (1988) The composition of extracellular interstitial fluid collected with a push-pull catheter from the testes of adult rats Journal of Physiology 407 363-372

Maddocks S and Setchell BP (1989a) Testosterone concentrations in testicular interstitial fluid collected with a push-pull catheter or by dripcollection from adult rats given testosterone or aminoglutethamide Journal of Endocrinology 121 303-309

Maddocks S and Setchell BP (1989b) Effects of a single injection of human chorionic gonadotrophin on testosterone levels in testicular interstitial fluid and in testicular and peripheral venous blood plasma in adult rats Journal of Endocrinology 121 311-316

Main SJ, Davies RV and Setchell BP (1978) Feedback control by the testis of gonadotropin secretion: an examination of the inhibin hypothesis Journal of Endocrinology 79 255-270

Meistrich ML and Kangasniemi M (1997) Hormone treatment after irradiation stimulates recovery of rat spermatogenesis from surviving spermatogonia Journal of Andrology 18 80-87

Meistrich ML, Parchuri N, Wilson G, Kurdoglu B and Kangasniemi M (1995) Hormonal protection from cyclophosphamide-induced inactivation of rat stem spermatogonia Journal of Andrology 16 334-341

Meistrich ML, Wilson G, Ye W-S, Thrash C and Huhtaniemi I (1996) Relationship among hormonal treatments, suppression of spermatogenesis, and testicular protection from chemotherapy-induced damage Endocrinology 137 3823-3831

Meistrich ML, Wilson G, Kangasniemi M and Huhtaniemi I (2000) Mechanisms of protection of rat spermatogenesis by hormonal pretreatment: stimulation of spermatogonial differentiation after irradiation Journal of Andrology 21 464-469

Miraglia SM and Hayashi H (1993) Histomorphometry of immature rat testis after heating Journal of Morphology 217 65-74

Reid BO, Mason KA, Withers HR and West J (1981) Effects of hyperthermia and radiation on mouse testis stem cells Cancer Research 41 4453-4457 
Robb GW, Amann RP and Killian GJ (1978) Daily sperm production and epididymal sperm reserves of pubertal and adult rats Journal of Reproduction and Fertility 54 103-107

Russell LD, Ettlin RA, Sinha Hikim AP and Clegg ED (1990) Histological and Histopathological Evaluation of the Testis Cache River Press, Clearwater, FL

Setchell BP (1998) The Parkes lecture: heat and the testis Journal of Reproduction and Fertility 114 179-194

Setchell BP and Waites GMH (1972) The effects of local heating on the flow and composition of rete testis fluid in the rat, with some observations of the effects of age and unilateral castration Journal of Reproduction and Fertility 30 225-233

Setchell BP, Hinton BT, Jacks F and Davies RV (1976) Restricted penetration of iodinated follicle-stimulating and luteinizing hormone into the seminiferous tubules of the rat testis Molecular and Cellular Endocrinology 6 59-69

Setchell BP, Tao L and Zupp JL (1996) The penetration of chromium-EDTA from blood plasma into various compartments of rat testes, as an indicator of function of the blood-testis barrier, following exposure of the testes to heat Journal of Reproduction and Fertility $\mathbf{1 0 6}$ 125-133

Shetty G, Wilson G, Huhtaniemi I, Shuttlesworth GA, Reissmann T and Meistrich ML (2000) Gonadotrophin-releasing hormone analogs stimulate and testosterone inhibits the recovery of spermatogenesis in irradiated rats Endocrinology 141 1735-1745
Shuttlesworth GA, De Rooij DG, Huhtaniemi I, Reissmann T, Russell LD, Shetty G, Wilson G and Meistrich ML (2000) Enhancement of A spermatogonial proliferation and differentiation in irradiated rats by gonadotropin-releasing hormone antagonist administration Endocrinology 141 37-49

Tao L, Zupp JL and Setchell BP (2000) Effect of efferent duct ligation on the function of the blood-testis barrier in rats Journal of Reproduction and Fertility 120 13-18

Turner TT, Jones CE, Howards SS, Ewing LL, Zegeye B and Gunsalus GL (1984) On the androgen microenvironment of maturing spermatozoa Endocrinology 115 1925-1932

Zupp JL, Maddocks S and Setchell BP (1988) K and Na in interstitial extracellular fluid in rat testes Journal of Reproduction and Fertility Abstract Series 1 Abstract 37

Received 22 November 2000.

First decision 22 January 2001

Final revision received 30 March 2001.

Accepted 5 April 2001. 